THE EFFECT OF MIDKINE ON GROWTH FACTORS AND OXIDATIVE STATUS IN AN EXPERIMENTAL WOUND MODEL IN DIABETIC AND HEALTHY RATS

\begin{tabular}{|r|l|}
\hline Journal: & Canadian Journal of Physiology and Pharmacology \\
\hline Manuscript ID & cjpp-2016-0439.R1 \\
\hline Manuscript Type: & Article \\
\hline Date Submitted by the Author: & 27-Oct-2016 \\
\hline Complete List of Authors: & $\begin{array}{l}\text { DiK, BURAK; Selcuk Universitesi, Veterinary Faculty. Pharmacology and } \\
\text { Toxicology Department } \\
\text { Bas, Ahmet Levent; Selcuk University, Faculty of Veterinary Medicine, } \\
\text { Pharmacology and Toxicology } \\
\text { Yazihan, Nuray; Ankara University, Faculty of Medicine }\end{array}$ \\
\hline Keyword: & \begin{tabular}{l} 
Midkine, wound healing, growth factors \\
\hline
\end{tabular} \\
\hline
\end{tabular}




\title{
THE EFFECT OF MIDKINE ON GROWTH FACTORS AND OXIDATIVE STATUS IN AN EXPERIMENTAL WOUND MODEL IN DIABETIC AND HEALTHY RATS
}

\section{Running title: Midkine affects growth factors in wound healing in rats}

\author{
Dik Burak $^{1 *}$, Baş Ahmet Levent ${ }^{1}$, Yazıhan Nuray $^{2}$ \\ ${ }^{1}$ Department of Pharmacology and Toxicology, Veterinary Faculty, University of Selcuk, Konya, Turkey \\ ${ }^{2}$ Department of Pathophysiology, Medicine Faculty, University of Ankara, Ankara, Turkey
}

* Corresponding Author : Burak DiK, Department of Pharmacology and Toxicology, Faculty of Veterinary Medicine, University of Selcuk, 42130, Konya, Turkey. E-Mail: burakdik@selcuk.edu.tr, Tel: +90 (332) 2232684 - Fax: +90 (332) 2410063. 
1 Abstract

2 Wound healing is important for long life. Midkine is a cytokine involved in controlling tissue

3 repair and new tissue development, and regulating inflammation. We investigated the effect

4 of midkine on wound healing in rats. In total, 108 Wistar albino rats were used: 12 as healthy

5 and diabetic controls; 96 split into four groups: healthy, saline treated (HW); healthy, midkine

6 (10 ng/kg, 48-hourly intervals) treated (HM); diabetic, saline treated (DW); and diabetic,

7 midkine treated (DM). Following wound creation, 6 rats per group were euthanized on days 3,

8 7, 14 and 28; the wounded skin was removed. Levels of epidermal growth factor (EGF),

9 matrix metalloproteinase-8 (MMP-8), transforming growth factor beta (TGF- $\beta$ ), platelet

10 derived growth factor (PDGF), vascular endothelial growth factor (VEGF) and thiobarbituric

11 acid-reactive substances (TBARS) were measured. MMP-8 and PDGF levels fluctuated in all

12 groups; TGF- $\beta$ fluctuated in the diabetic groups and was significantly higher in the HM group

13 than other groups after 14 days. EGF and VEGF levels were increased in the HM group after

143 days. TBARS levels were highest in the diabetic groups. Macroscopically, the midkine

15 treated groups healed better. Midkine can accelerate wound healing by influencing growth

16 factors and oxidative status in wound tissues.

17 Keywords: Midkine; wound healing; growth factors. 


\section{Introduction}

A wound is defined as the impairment of tissue or organ integrity. The normal wound healing process is a well-orchestrated, complex and interlinked series of different processes (Guo and DiPietro 2010). Systemic problems often impair the phases of wound healing and nonhealing wounds may herald systemic pathologies, with delayed wound healing serving as a source of morbidity and mortality in chronic diseases because of the associated tissue inflammation and infection. For years, many researchers have focused on discoveries that could support the healing of skin wounds. A variety of chemicals and drugs have been tested to improve the quality and strength/speed of wound healing. There are no perfect drugs, although there are many that are promising (Rhett et al. 2008).

Macrophages, fibroblasts, platelets, endothelial cells and keratinocytes play important roles during wound healing. They provide a storehouse of growth factors, cytokines and chemoattractant molecules. Epidermal growth factor (EGF) acts in the formation of new epidermis. It increases collagen accumulation and induces proliferation of epidermal cells and keratinocyte migration, and in doing so strength/speed the healing of wounds (Kondo and Ishida 2010; Seeger and Paller 2015). Along with matrix metalloproteinase (MMP), transforming growth factor beta (TGF- $\beta$ ) supplies new matrix. MMP allows modulation, coordination of wound healing and organization of granulation tissue (Kondo and Ishida 2010; Martins et al. 2013). It also contributes to the migration of cells/structures (Martins et al. 2013). Platelet derived growth factor (PDGF) allows chemotaxis and mitogenesis of neutrophils and macrophages, and conversion of fibroblasts to myofibroblasts and smooth muscle cells (Barrientos et al. 2008; Werner and Grose 2003). It accelerates wound healing (Judith et al. 2010). PDGF is the only FDA-approved growth factor for diabetic wound healing (Brem and Tomic-Canic 2007). It acts synergistically with TGF- $\beta$ (Barrientos et al. 2008; Werner and Grose 2003). TGF- $\beta$ stimulates the synthesis of collagen and inhibitors of 
44 MMP. It plays an important role in inflammation, angiogenesis, re-epithelialization and 45 connective tissue regeneration (Faler et al. 2006). In addition, it aids the formation of granulation tissue and plays a part in all steps of wound healing (Kondo and Ishida 2010). Vascular endothelial growth factor (VEGF) plays an essential role in the proliferation and formation of new endothelial cells. It promotes formation of new blood vessels (Barrientos et al. 2008; Kondo and Ishida 2010).

The oxidative state of a wound is a key determinant of its healing outcome. Levels of thiobarbituric acid-reactive species (TBARS) and malondialdehyde (MDA) depend on the level of free radicals. The increased accumulation of free radicals induces lipid peroxidation in the wound area. Therefore, it has been shown that antioxidants may be helpful in wound healing (Rasik and Shukla 2000).

The cytokine midkine (MK) is a heparin-binding growth factor of $13 \mathrm{kDa}$ (Muramatsu 2011). It promotes cell growth, cell migration, chemotaxis, and fibrinolysis, as well as embryogenesis and survival by influencing the mitogen-activated protein kinase (MAPK) and phosphatidyl inositol 3-kinase (PI3K)/AKT pathways (Xu et al. 2014). MK induces epithelial-mesenchymal interactions, neurogenesis, angiogenesis, anti-apoptosis and migration in embryogenesis (Muramatsu 2010). Because of its properties and physiological functions, MK could be effective in wound treatment trials (Unoki et al. 1995). MK affects regulation of inflammation, growth of fibroblasts and keratinocytes, cell proliferation, inflammatory cell migration (macrophages and neutrophils, among others) and the formation of the cytoskeleton, an effect it provides through the receptor tyrosine phosphatase (RPTP- $\beta$ ) (Muramatsu 2011; Sumi et al. 2000). MK levels may be associated with the levels of the growth factors that can assist healing (Kadomatsu et al. 2014). MK reduces apoptosis, and increases cell viability and proliferation. It also reverses hypoxia-induced increases in intracellular reactive oxygen species (Lee et al. 2012). 
69

Diabetes is a chronic disease with dysregulation of glucose, which also leads to lipid and protein metabolism disorders. It can cause a number of complications, including some that make it harder for wounds to heal. Impaired wound healing is a frequent and very severe problem in patients with diabetes mellitus. The nonenzymatic glycation of proteins, generating advanced glycation end-products, acts as an active pathogenic stream that affects healing (Dagogo-Jack and Alberti 2002). The excessive apoptosis, increased matrix degradation and disintegration of the cell matrix connections associated with hyperglycemia cause delays in wound healing (Darby et al. 1997). In addition, irregular inflammatory responses, impairment of inflammatory cell migration, prolonged inflammation, impaired neovascularization and unbalanced collagen expression retard wound healing in diabetic patients (Ahmed 2005).

In this research, it hass been hypothesized that effects of MK on the some inflammatory biological markers which play role in the healing of wound (Muramatsu 2010) are taken into consideration; MK may show some beneficial effect in the wound healing in the healthy or diabetic subjects.

The costs of treating pathologies related to this deficit in the healing process increase the importance of studies searching for new treatment approaches that are capable of interacting with damaged tissues to accelerate the healing process/treatments. In this study, we aimed to evaluate the effect of MK application to a full-thickness skin wound model in healthy and diabetic rats.

\section{Materials and Methods}

\section{Animals}


A total of 108 male Wistar albino rats (10-12 weeks, $250-350 \mathrm{~g})$ were housed in cages in a room with automatic ambient humidity $(55 \pm 5 \%)$, temperature $\left(22 \pm 2^{\circ} \mathrm{C}\right)$, and light-dark control (12-h light/dark cycle). The animals were obtained from the KONUDAM Experimental Medicine, Application and Research Center, Konya, Turkey. They were fed ad libitum with a commercial diet (Bil-Yem Feeds, Ankara, Turkey) that included the following: $88 \%$ dry matter, $23 \%$ crude protein, $7 \%$ crude fibre, $3 \%$ crude oil, $1.0-2.5 \%$ calcium, $0.9 \%$ phosphorus and $0.5-1 \%$ sodium, and had free access to water.

All experiments and manipulations were carried out in accordance with the Guide for the Care and Use of Laboratory Animals (1996, published by National Academy Press, 2101 Constitution Ave. NW, Washington, DC 20055, USA) and our use of animals was reviewed and approved by the appropriate animal care review committee at the Ethics Committee of Necmettin Erbakan University Kombassan Experimental Medicine Research and Application Center, Turkey.

\section{Induction of diabetes}

Streptozotocin (STZ, $\geq 98 \%$ [HPLC], Sigma-Aldirich Co., USA) dissolved in citrate buffer $(\mathrm{pH} 4.5,20 \mathrm{mg} / \mathrm{mL})$ was used to induce diabetes, with two consecutive daily subcutaneous (s.c.) doses of freshly prepared STZ (40 mg/kg) being given (Gelling et al. 2006). The rats were allowed to drink 5\% glucose solution overnight to accomplish the drug-induced hypoglycemia (Liang et al. 2013). Rats with nonfasting blood glucose levels of $\geq 300 \mathrm{mg} / \mathrm{dL}$ 2 weeks after STZ injection were considered to be diabetic (Haidara et al. 2009).

\section{Experimental design and full-thickness skin wound model}

First, 12 Wistar albino rats were divided into two groups (6 healthy [H group] and 6 diabetic [D group] to act as the controls (Hour 0). The dorsal skin of these animals that did not undergo application of MK or saline was removed under anesthesia at 0 hour. 
116 The remaining 96 rats were divided into four procedure groups: healthy control (HW), healthy 117 midkine (HM), diabetic control (DW), and diabetic midkine (DM), giving 24 rats per group.

118 The dorsal skins of these 96 animals were shaved and cleaned with iodine solution. With the 119 animals under anesthesia, four full-thickness skin wounds (approximately $6 \mathrm{~mm}$ in diameter)

120

121

122

123

124

125

126

127

128

129

130

131

132

133

134

135

136

137

were created using a 6-mm biopsy punch at 0 hour (diabetes mellitus having been previously established in the two diabetic groups).

In two groups (HW and DW), the wound area of the rats was treated with $0.9 \%$ saline solution (s.c.) at 48-hourly intervals during the study period.

In the remaining two groups (HM and DM), the wound area of the rats was treated with MK solution (10 ng/kg, s.c.; Sigma-Aldirich Co.) at 48-hourly intervals during the study period.

From each of these groups, six rats were examined at each of four time points $(3,7,14$, and 28 days). The wounded skin was collected at the appropriate sampling time, with the rats anesthetized using $20 \mathrm{mg} / \mathrm{kg}$ intraperitoneal thiopental sodium (Pental $1 \mathrm{~g}$; Ulagay, Istanbul, Turkey).

\section{Evaluation of wound healing}

The wound granulation tissues were harvested at each time point. Harvested skins were stored at $-80^{\circ} \mathrm{C}$ for further analysis. The concentrations of growth factors were measured using an ELISA reader (Bio-Tek Instruments Inc., MWGt Lambda Scan 200) and the following ratspecific ELISA kits: EGF, PDGF, TGF- $\beta$ (USCN Business Co., Ltd., USA); MMP-8, VEGF (Cusabio, China); and TBARS (Cayman Chemical, USA) according to the manufacturer's protocol.

\section{Statistical analysis}


All experimental values are presented as mean \pm SE. The data were analyzed by ANOVA, and the Duncan test was then used as a post-hoc test to analyze the difference between the groups and across the days (IBM SPSS Statistics 22.0). $P<0.05$ was considered significant.

\section{Results}

EGF levels in HW group were lower than in all of the other groups at day $3(\mathrm{P}<0.05)$, while EGF levels in the HM group were higher than all of the other groups at day $28(\mathrm{P}<0.05)$. In the HM group, the levels increased steadily across the sampling days and the levels on days 14 and 28 were statistically significantly $(\mathrm{P}<0.05)$ higher than at 0 hour $($ Table 1$)$.

MMP-8 levels were highest $(\mathrm{P}<0.05)$ on days 3 and 7 in the HW group, compared with the other groups. In the HW group, the MMP-8 level was highest on day 3, compared with the other days $(\mathrm{P}<0.05)$, however, MMP-8 levels reduced from 0 hour in the DM group $(\mathrm{P}<$ $0.05)$ (Table 1).

The PDGF level was higher in the DW group than the other groups on day $3(\mathrm{P}<0.05)$ and it was higher in the HM group than the HW and DW groups on day 14. In the other words, levels of PGDF were found to fluctuate across the days, with the levels being highest on days 7, 14, 3 and 14 in the HW, HM, DW and DM groups, respectively $(\mathrm{P}<0.05)$. At 0 hour and on day 28, PDGF levels were determined to be lowest in the HW group. In contrast, the other groups were observed to be low only at 0 hour $(\mathrm{P}<0.05)$ (Table 1$)$.

The TGF- $\beta$ level of the DW group was higher than the other groups on day $3(\mathrm{P}<0.05)$. When the HM group was compared with the HW group, the TGF- $\beta$ level was higher $(\mathrm{P}<$ 0.05 ) on days 14 and 28 and its highest level was found in the HM group on day 28. In the HM group, TGF- $\beta$ level was higher at 0 hour compared with day $28(\mathrm{P}<0.05)$. Fluctuations were seen in the TGF- $\beta$ levels of the DW group. The TGF- $\beta$ level decreased in the DW group 
162 after day $3(\mathrm{P}<0.05)$, whereas in the DM group the highest TGF- $\beta$ level was detected on day $16314(\mathrm{P}<0.05)$ (Table 1).

164

165

166

167

168

169

170

171

172

173

174

175

176

177

178

VEGF levels increased in the DM and HM groups up until day 14. The VEGF level was higher in the HW group than in the DM group on day $3(\mathrm{P}<0.05)$. This level was shown to be highest in the HM group on day 7 among the groups and the level of VEGF was lower in the DW group than in the HM group on day 14 (Table 1).

TBARS levels decreased in the HW group after 0 hour $(\mathrm{P}<0.05)$. In the diabetic groups, TBARS levels were found to be very high at 0 hours, but levels reduced after the wound was created $(\mathrm{P}<0.05)$. At 0 hours, there was a significant difference between the healthy and the diabetic groups $(\mathrm{P}<0.05)$. In the same time, the TBARS level was highest in the DW group on day $28(\mathrm{P}<0.05)$ among the groups (Table 1$)$.

\section{Discussion}

The repair of cutaneous wounds in the adult body involves a complex series of spatially and temporally organized processes to prevent infection and restore homeostasis that last months and years. Three characteristic phases of wound repair (inflammation, proliferation including re-epithelialization, and remodeling) overlap in time and space. Extracellular matrix, inflammatory mediators and a wide range of growth factors take part in these cascades; these factors are now being increasingly recognized as an important modality for accelerating and modulating healing processes ( $\mathrm{Li}$ et al. 2007). MK plays a part in proliferation, growth, migration and survival of different cell types. In addition, it induces synthesis of extracellular matrix proteins and regeneration of the basic structures that form the cell skeleton (Kadomatsu et al. 2014; Shirakata et al. 2005; Sumi et al. 2000). MK is a cytokine or growth factor that has a similar structure to other growth factor-related protein families, such as the 
186 fibroblast growth factor family and neuronal growth factors (Kosugi et al. 2006). MK may

187 have different effects in inflammatory pathologies.

Levels of EGF increased in MK-treated healthy rats (Table 1). EGF accelerates wound healing and supports skin morphogenesis and homeostasis (Barrientos et al. 2008; Kondo and Ishida 2010). The presence of keratinocytes is necessary, when normal wound healing (specifically epidermis and hairs) is required. In this case, EGF ensures regulation and migration of keratinocytes and hemostasis in the skin (Blumenberg 2013; Nanba et al. 2013). At the same time, it supplies new epithelium, promoting formation of matrix and cell proliferation (Santoro and Gaudino 2005; Shirakata et al. 2005). Hence, epithelialization is accelerated in wound areas by the migration of increased numbers of keratinocytes (Shirakata et al. 2005). Wound healing is delayed when keratinocytes and fibroblast cells are inhibited (Cho Lee et al. 2005).

MK can have influence on keratinocytes directly or can affect the synthesis of growth factors from inflammatory cells indirectly, so increasing rates of wound closure and hair growth. As a result, EGF may have increased the number of keratinocytes in the HM group, leading to the faster wound healing and hair growth that occurred in this group. However, these features were not at the desired level because of fluctuating EGF levels in the DW and DM groups. It may be that high glucose concentrations impair proliferation and differentiation in keratinocytes, and affect the growth factors released from macrophages (Maruyama et al. 2007; Spravchikov et al. 2001). For these reasons, the regenerative effect of MK on wound healing is not absolutely proven in the diabetic group because this group might have a lack of normal cells such as macrophages and keratinocytes in comparison with healthy animals. In addition, increased EGF and glucose levels may have induced excessive endogenous MK levels (Rawnaq et al. 2014). Therefore, wound healing may have been partially delayed in the DM group compared with the HM group. 
211 It is suggested that epidermal healing and hair growth are delayed because of the fluctuations

212 in EGF levels in the diabetic groups (Table 1). However, this may depend on increases in the 213 number of keratinocytes as higher EGF levels can speed up hair growth and wound healing in 214 the HM group. It is reported that EGF reduces the formation of scars, and accelerates 215 vascularization and wound healing. In addition, it is reported to increase collagen levels (Xing et al. 2013). In the present study, increased EGF levels may have raised the amount of 217 collagen and vascularity in the HM group, in which, scarless and early wound healing was 218 observed.

In the present study, MMP-8 levels statistically fluctuated in the HW group, whereas, in the other groups, they were linear. However, MMP-8 levels were very low in the diabetic groups (Table 1). MMP-8 is the predominant collagenase involved in healing wounds (Nwomeh et al. 1999). MMP degrades extracellular matrix helping the migration of cells, the deposition of new matrix and the development of new tissue. MMP regulates the balance between tissue synthesis and degradation that is required for inflammation and regeneration. Tissue inhibitors of MMP (TIMP) strongly inhibit the effects of MMP (Martins et al. 2013; Xue et al. 2006). TGF- $\beta$ stimulates TIMP and the protease inhibitor (Diegelmann and Evans 2004). For this reason, MK cannot affect MMP-8 levels sufficiently. Excessive degradation of the extracellular matrix due to MMP leads to increased diabetic wounds and delays in wound healing (Martins et al. 2013; Xue et al. 2006). MMP-8 derives from inflammatory cells that are necessary for normal wound healing, especially in the early phase. If these cells are insufficient, wound healing is delayed (Gutierrez-Fernandez et al. 2007).

Treatment with MK increased PDGF levels in the proliferation and remodeling phase of wound healing in the present study (Table 1). PDGF is important in various stages of wound healing. It is a chemoattractant, particularly of fibroblasts, collagen, neutrophils and monocytes. It regulates contraction of wounds and formation of granulation tissue. PDGF 
236 levels are reported to be decreased in diabetics (Santoro and Gaudino 2005). Application of

237 PDGF in a wound increases re-epithelization, vascularity and the maturation rate of 238 granulation tissue (Cheng et al. 2007).

239 In the present study, the formation rate of granulation tissue, angiogenesis, fibroblasts and 240 collagen may have increased because MK increased PDGF levels. Therefore, this can produce 241 better wound healing in the HM and DM groups. However, the effect of PDGF alone may be 242 insufficient for wound healing in the DM group.

243 TGF- $\beta$ levels were enhanced by MK treatment in the present study, with a significant increase 244 in the HM group (Table 1). TGF- $\beta$ is released by platelets, macrophages and T lymphocytes. 245 TGF- $\beta$ is the main control signal that organizes fibroblast function and extracellular matrix 246 deposition (Diegelmann and Evans 2004). It helps with the activation of macrophages, 247 stimulation of angiogenesis, migration of keratinocytes, accumulation of collagen, and re248 epithelization (Rhett et al. 2008; Santoro and Gaudino 2005). In this way, TGF- $\beta$ may have 249 raised own release from keratinocytes and macrophages (Kondo and Ishida 2010). As a result, 250 decreased TGF- $\beta$ levels are reported to delay wound healing (Crowe et al. 2000) and levels 251 are insufficient in diabetics (Jude et al. 2002).

252 MK may enhance keratinocyte numbers because MK increases the TGF- $\beta$ level and so can 253 accelerate hair growth and wound healing. Hair growth and wound healing was slower in the 254 DM group compared with the HM group because the TGF- $\beta$ level fluctuated, particularly in 255 the final stages of wound healing. Wound healing is delayed in diabetic rats because of the 256 abnormal inflammatory response, such as lack of neutrophils (Komesu et al. 2004). In the 257 present study, MK may affect inflammatory cells and the release of their growth factors 258 (TGF- $\beta$ and EGF, among others). In addition, wound healing and hair growth showed a 259 greater improvement in healthy rats compared with diabetic rats. 
260 The quantity and exposure time of MK is reported to result in changes in collagen synthesis 261 and the usage of a $100 \mathrm{ng} / \mathrm{mL}$ dose in vitro has been recommended (Yamada et al. 1997). In 262 the present study, treatment with MK may have increased collagen and accelerated wound 263 healing because of a rise in TGF- $\beta$ levels. As a result, MK may be increasing the synthesis of 264 collagen directly and indirectly.

In the present study, VEGF levels increased in the HM group (Table 1). Angiogenesis is an essential element in normal wound healing. VEGF promotes blood vessel regeneration during repair (Diegelmann and Evans 2004). Keratinocytes and macrophages are the source for angiogenic factors (Rossiter et al. 2004). Because MK may have induced these cells, angiogenesis and rapid wound healing may have occurred.

The amount of VEGF was lower in the diabetic groups in the present study (Table 1). It is well known that collagen, granulation tissue and new vessels are insufficient in diabetics, mainly due to the lower levels of angiogenic factors (VEGF and angiopoietin 2, among others) and inflammatory cells compared with healthy subjects (Blakytny and Jude 2006; Sharma et al. 2006). Topical VEGF application to diabetic mice contributes to blood vessel formation in the local wound environment and accelerates repair (Galiano et al. 2004). MK plays a critical role on inflammatory cells (polymorphonuclear neutrophils and macrophages, among others) during acute inflammation (Weckbach et al. 2014). MK may have induced angiogenic factors in the early phase of wound healing in healthy rats, but it had no similar effect in the diabetic rats because of an insufficiency of angiogenic and inflammatory cells. It can provide growth factors synthesis such as VEGF so for this reason may have induced angiogenic factors and epithelization in the HM group but not in other groups. Therefore, MK can accelerate angiogenesis and wound healing in healthy groups. 
283 In the current research, the TBARS level was very high in the diabetic groups at 0 hour (Table

284 1). Polyunsaturated fatty acid peroxidation causes oxidative stress and damage to cells

285 affected by certain diseases such as diabetes (Del Rio et al. 2005). Excessive oxidative stress

286 disrupts the effects of fibroblasts and the response of fibroblasts to growth factors (Soneja et

287 al. 2005). For this reason, the effects of fibroblasts and cells involved in wound healing are

288 damaged in the diabetics groups. After the wound had been created, the TBARS levels were

289 similar between the healthy and diabetic groups, because the test materials (skin samples)

290 were developing new granulation tissue. The main molecule on assays of TBARS is MDA

291 (Del Rio et al. 2005), which is high and leads to incomplete wound healing in diabetics

292 compared to healthy subjects. Hyperglycemia causes apoptosis (Arya et al. 2011). Wound

293 healing in diabetic groups with very high levels of TBARS may be delayed because of

294 excessive apoptosis.

295 MK is reported to be a potent stimulator of glycosaminoglycan and collagen synthesis and it 296 is suggested to be helpful in the treatment of delayed wound healing (Yamada et al. 1997). In

297 one trial, an ischemic wound was found to delay healing and wound healing accelerated after 298 day 7 because of a reduction in ischemia (Chen et al. 1999). Hence, MK can affect collagen 299 synthesis and angiogenesis in the inflammatory phase because of its influence on 300 inflammatory cells that release growth factors (VEGF, TGF- $\beta$, etc.), and can be protective 301 against hypoxia. This mechanism explains the increase in angiogenesis and oxygenation 302 because MK improves the expression of VEGF, TGF- $\beta$ and insulin-like growth factor-1 303 (Zhao et al. 2014). MK may improve angiogenesis and wound healing because it increases 304 levels of VEGF and TGF- $\beta$ in the HM group. In addition, it partly supplied these growth 305 factors and improved wound healing in the DM group; however, it was not as good as in the 306 healthy rats. Wound healing is delayed because of lack of neutrophils, macrophages, pro- 
307 inflammatory mediators and excessive apoptosis in the early phase, after which inflammation 308 continues uncontrolled (Koh and DiPietro 2011).

Inflammatory or immune cells in nonhealing diabetic wounds cause impairments in the expression of growth factors, extracellular matrix formation, angiogenesis and reepithelialization (Ochoa et al. 2007). MK may possibly control inflammation in the early phase of wound healing. Delayed wound healing in diabetes is a very complex situation, with uncontrolled inflammation and late angiogenesis, and other reasons. MK is known to increase synthesis of extracellular matrix molecules and it can be of use in burns and skin damage. It has greater effects in the early phase compared with the late phase in vitro (Sumi et al. 2000).

As a result, MK can show different effects in different stages. MK interacts with specific integrin molecules (Muramatsu et al. 2004), which ensure contact in the cell and movement of cells. Integrin molecules have $\alpha$ and $\beta$ subtype. On migration of cells, endothelial cells have a high affinity to these subtypes (Falanga 2005). MK binds to integrin subtypes and activates adapter protein of paxillin in the cell, allowing the tyrosine phosphorylation of the protein.

Phosphorylated paxillin increases the stimulation of growth factors (Muramatsu et al. 2004). In addition, it promotes cell motility, transformation and maturation. Macrophages, lymphocytes and smooth muscle cells have abundant paxillin (Turner 1998). To our best knowledge, there was no any research about MK relationship wound healing in diabetic and healthy subjects; hence effects of MK on the EGF, VEGF, MMP-8, TGF- $\beta$, PDGF and TBARS have not been evaluated, which are very important factors in the wound healing. Beneficial effects of MK on the wound healing may be derived from effecting of MK on cell migration and the release of growth factors by activating intracellular proteins such as paxillin. However, MK cannot affect the deficiency or disorder of the inflammatory cells in diabetics, meaning that wound healing is more regular and rapid in the HM group than in the DM group. 


\section{Conclusions and Suggestions}

333

334

Wound healing depends on many factors (levels of growth factors and cytokines) and different cells (keratinocytes and endothelial cells, etc) and is different in diabetic subjects from healthy subjects. MK may show different effects in healthy and diabetic subjects because of its effects on the inflammatory cells that are present at low levels in diabetics. MK may affect many growth factors, cytokines and some other factors in cells. It may affect angiogenesis, formation of new matrix and accelerate the development of new epidermis. MK may increase hair growth and wound healing. In addition, its effect may be more powerful in the early stages of wound healing.

MK may be more effective in wound healing among healthy subjects than diabetics, but it could possibly be utilized with different drugs that are effective in diabetics, although its effects may change depending on time and affected cells. In the future, the effects of MK on wound healing should be researched in more detail and it may provide a new treatment strategy for wound healing. Further investigations or clinical studies are needed to determine the specific cellular target or other effects of MK.

\section{Acknowledgments}

This article was summarized from the $\mathrm{PhD}$ thesis of the first named author. This study is supported by SUPABK (12102003) and BSTB (0443.Stz.2013-2). A part of the abstract was presented as a poster at the 5th International Congress on Cell Membranes and Oxidative Stress Congress, Isparta, Turkey, and the abstract was printed in the book of proceedings. We thank Dr. Enver Yazar for scientific assistance.

\section{Conflict of Interest}


The authors declare that no conflict of interests exists.

356

357

358

359

360

361

362

363

364

365

366

367

368

369

370

371

372

373

374

375

376

377

378

379

380

381

382

383

384

385

386

387

388

389

390

391

\section{References}

Ahmed, N. 2005. Advanced glycation endproducts--role in pathology of diabetic complications. Diabetes. Res. Clin. Pract., 67(1): 3-21. doi: 10.1016/j.diabres.2004.09.004.

Arya, A.K., Pokharia, D., and Tripathi, K. 2011. Relationship between oxidative stress and apoptotic markers in lymphocytes of diabetic patients with chronic non healing wound. Diabetes. Res. Clin. Pract., 94(3): 377-384. doi: 10.1016/j.diabres.2011.08.004.

Barrientos, S., Stojadinovic, O., Golinko, M.S., Brem, H., and Tomic-Canic, M. 2008. Growth factors and cytokines in wound healing. Wound. Repair. Regen., 16(5): 585-601. doi: 10.1111/j.1524-475X.2008.00410.x.

Blakytny, R., and Jude, E. 2006. The molecular biology of chronic wounds and delayed healing in diabetes. Diabet. Med., 23(6): 594-608. doi: 10.1111/j.1464-5491.2006.01773.x.

Blumenberg, M. 2013. Profiling and metaanalysis of epidermal keratinocytes responses to epidermal growth factor. BMC. Genomics., 14: 85. doi: 10.1186/1471-2164-14-85.

Brem, H., and Tomic-Canic, M. 2007. Cellular and molecular basis of wound healing in diabetes. J. Clin. Invest., 117(5): 1219-1222. doi: 10.1172/JCI32169.

Chen, C., Schultz, G.S., Bloch, M., Edwards, P.D., Tebes, S., and Mast, B.A. 1999. Molecular and mechanistic validation of delayed healing rat wounds as a model for human chronic wounds. Wound. Repair. Regen., 7(6): 486-494.

Cheng, B., Liu, H.W., Fu, X.B., Sun, T.Z., and Sheng, Z.Y. 2007. Recombinant human platelet-derived growth factor enhanced dermal wound healing by a pathway involving ERK and c-fos in diabetic rats. J. Dermatol. Sci., 45(3): 193-201. doi: 10.1016/j.jdermsci.2006.11.014.

Cho Lee, A.R., Leem, H., Lee, J., and Park, K.C. 2005. Reversal of silver sulfadiazineimpaired wound healing by epidermal growth factor. Biomaterials., 26(22): 4670-4676. doi: 10.1016/j.biomaterials.2004.11.041.

Crowe, M.J., Doetschman, T., and Greenhalgh, D.G. 2000. Delayed wound healing in immunodeficient TGF-beta 1 knockout mice. J. Invest. Dermatol., 115(1): 3-11. doi: 10.1046/j.1523-1747.2000.00010.x.

Dagogo-Jack, S., and Alberti, K.G.M. 2002. Management of diabetes mellitus in surgical patients. Diabetes. Spectr., 15(1): 44-48.

Darby, I.A., Bisucci, T., Hewitson, T.D., and MacLellan, D.G. 1997. Apoptosis is increased in a model of diabetes-impaired wound healing in genetically diabetic mice. Int. J. Biochem. Cell. Biol., 29(1): 191-200.

Del Rio, D., Stewart, A.J., and Pellegrini, N. 2005. A review of recent studies on malondialdehyde as toxic molecule and biological marker of oxidative stress. Nutr. Metab. Cardiovasc. Dis., 15(4): 316-328. 
Diegelmann, R.F., and Evans, M.C. 2004. Wound healing: An overview of acute, fibrotic and delayed healing. Front. Biosci., 9: 283-289. doi: Doi 10.2741/1184.

Falanga, V. 2005. Wound healing and its impairment in the diabetic foot. Lancet., 366(9498): 1736-1743. doi: 10.1016/S0140-6736(05)67700-8.

Faler, B.J., Macsata, R.A., Plummer, D., Mishra, L., and Sidawy, A.N. 2006. Transforming growth factor-beta and wound healing. Perspect. Vasc. Surg. Endovasc. Ther., 18(1): 55-62. doi: $10.1177 / 153100350601800123$.

Galiano, R.D., Tepper, O.M., Pelo, C.R., Bhatt, K.A., Callaghan, M., Bastidas, N., Bunting, S., Steinmetz, H.G., and Gurtner, G.C. 2004. Topical vascular endothelial growth factor accelerates diabetic wound healing through increased angiogenesis and by mobilizing and recruiting bone marrow-derived cells. Am. J. Pathol., 164(6): 1935-1947. doi: Doi 10.1016/S0002-9440(10)63754-6.

Gelling, R.W., Morton, G.J., Morrison, C.D., Niswender, K.D., Myers, M.G., Rhodes, C.J., and Schwartz, M.W. 2006. Insulin action in the brain contributes to glucose lowering during insulin treatment of diabetes. Cell. Metab., 3(1): 67-73.

Guo, S., and DiPietro, L.A. 2010. Factors Affecting Wound Healing. J. Dent. Res., 89(3): 219-229. doi: Doi 10.1177/0022034509359125.

Gutierrez-Fernandez, A., Inada, M., Balbin, M., Fueyo, A., Pitiot, A.S., Astudillo, A., Hirose, K., Hirata, M., Shapiro, S.D., Noel, A., Werb, Z., Krane, S.M., Lopez-Otin, C., and Puente, X.S. 2007. Increased inflammation delays wound healing in mice deficient in collagenase-2 (MMP-8). FASEB. J., 21(10): 2580-2591. doi: 10.1096/fj.06-7860com.

Haidara, M.A., Mikhailidis, D.P., Rateb, M.A., Ahmed, Z.A., Yassin, H.Z., Ibrahim, I.M., and Rashed, L.A. 2009. Evaluation of the effect of oxidative stress and vitamin E supplementation on renal function in rats with streptozotocin-induced Type 1 diabetes. J. Diabetes. Complications., 23(2): 130-136.

Jude, E.B., Blakytny, R., Bulmer, J., Boulton, A.J., and Ferguson, M.W. 2002. Transforming growth factor-beta 1, 2, 3 and receptor type I and II in diabetic foot ulcers. Diabet. Med., 19(6): 440-447.

Judith, R., Nithya, M., Rose, C., and Mandal, A.B. 2010. Application of a PDGF-containing 10.1016/j.lfs.2010.05.003.

Kadomatsu, K., Bencsik, P., Gorbe, A., Csonka, C., Sakamoto, K., Kishida, S., and Ferdinandy, P. 2014. Therapeutic potential of midkine in cardiovascular disease. Br. J. Pharmacol., 171(4): 936-944. doi: 10.1111/bph.12537.

Koh, T.J., and DiPietro, L.A. 2011. Inflammation and wound healing: the role of the macrophage. Expert. Rev. Mol. Med., 13: e23. doi: 10.1017/S1462399411001943.

Komesu, M.C., Tanga, M.B., Buttros, K.R., and Nakao, C. 2004. Effects of acute diabetes on rat cutaneous wound healing. Pathophysiology., 11(2): 63-67. doi: 10.1016/j.pathophys.2004.02.002.

Kondo, T., and Ishida, Y. 2010. Molecular pathology of wound healing. Forensic. Sci. Int., 203(1): 93-98. 
Kosugi, T., Yuzawa, Y., Sato, W., Kawai, H., Matsuo, S., Takei, Y., Muramatsu, T., and Kadomatsu, K. 2006. Growth factor midkine is involved in the pathogenesis of diabetic nephropathy. Am. J. Pathol., 168(1): 9-19.

Lee, S.H., Suh, H.N., Lee, Y.J., Seo, B.N., Ha, J.W., and Han, H.J. 2012. Midkine prevented hypoxic injury of mouse embryonic stem cells through activation of Akt and HIF-1 $\alpha$ via lowdensity lipoprotein receptor-related protein-1. J. Cell. Physiol., 227(4): 1731-1739.

Li, J., Chen, J., and Kirsner, R. 2007. Pathophysiology of acute wound healing. Clin. Dermatol., 25(1): 9-18. doi: 10.1016/j.clindermatol.2006.09.007.

Liang, B., Guo, Z.D., Xie, F., and Zhao, A.N. 2013. Antihyperglycemic and antihyperlipidemic activities of aqueous extract of Hericium erinaceus in experimental diabetic rats. BMC Complement. Altern. Med., 13 (253): 1-7. doi: 10.1186/1472-6882-13253.

Martins, V.L., Caley, M., and O'Toole, E.A. 2013. Matrix metalloproteinases and epidermal wound repair. Cell. Tissue. Res., 351(2): 255-268. doi: 10.1007/s00441-012-1410-z.

Maruyama, K., Asai, J., Ii, M., Thorne, T., Losordo, D.W., and D'Amore, P.A. 2007. Decreased macrophage number and activation lead to reduced lymphatic vessel formation and contribute to impaired diabetic wound healing. Am. J. Pathol., 170(4): 1178-1191. doi: 10.2353/ajpath.2007.060018.

Muramatsu, H., Zou, P., Suzuki, H., Oda, Y., Chen, G.-Y., Sakaguchi, N., Sakuma, S., Maeda, N., Noda, M., and Takada, Y. 2004. $\alpha 4 \beta 1$-and $\alpha 6 \beta 1$-integrins are functional receptors for midkine, a heparin-binding growth factor. J. Cell. Sci., 117(22): 5405-5415.

Muramatsu, T. 2010. Midkine, a heparin-binding cytokine with multiple roles in development, repair and diseases. Proc. Jpn. Acad. Ser. B. Phys. Biol. Sci., 86(4): 410-425. doi: $10.2183 /$ pjab.86.410.

Muramatsu, T. 2011. Midkine: a promising molecule for drug development to treat diseases of the central nervous system. Curr. Pharm. Des., 17(5): 410.

Nanba, D., Toki, F., Barrandon, Y., and Higashiyama, S. 2013. Recent advances in the epidermal growth factor receptor/ligand system biology on skin homeostasis and keratinocyte stem cell regulation. J. Dermatol. Sci., 72(2): 81-86. doi: 10.1016/j.jdermsci.2013.05.009.

Nwomeh, B.C., Liang, H.X., Cohen, I.K., and Yager, D.R. 1999. MMP-8 is the predominant collagenase in healing wounds and nonhealing ulcers. J. Surg. Res., 81(2): 189-195. doi: DOI 10.1006/jsre.1998.5495.

Ochoa, O., Torres, F.M., and Shireman, P.K. 2007. Chemokines and diabetic wound healing. Vascular., 15(6): 350-355.

Rasik, A.M., and Shukla, A. 2000. Antioxidant status in delayed healing type of wounds. Int. J. Exp. Pathol., 81(4): 257-263.

Rawnaq, T., Dietrich, L., Wolters-Eisfeld, G., Uzunoglu, F.G., Vashist, Y.K., Bachmann, K., Simon, R., Izbicki, J.R., Bockhorn, M., and Güngör, C. 2014. The multifunctional growth factor midkine promotes proliferation and migration in pancreatic cancer. Mol. Cancer Res., 12(5): 670-680. 
Rhett, J.M., Ghatnekar, G.S., Palatinus, J.A., O'Quinn, M., Yost, M.J., and Gourdie, R.G. 2008. Novel therapies for scar reduction and regenerative healing of skin wounds. Trends. Biotechnol., 26(4): 173-180.

Rossiter, H., Barresi, C., Pammer, J., Rendl, M., Haigh, J., Wagner, E.F., and Tschachler, E. 2004. Loss of vascular endothelial growth factor a activity in murine epidermal keratinocytes delays wound healing and inhibits tumor formation. Cancer. Res., 64(10): 3508-3516.

Santoro, M.M., and Gaudino, G. 2005. Cellular and molecular facets of keratinocyte reepithelization during wound healing. Exp. Cell. Res., 304(1): 274-286. doi: 10.1016/j.yexcr.2004.10.033.

Seeger, M.A., and Paller, A.S. 2015. The Roles of Growth Factors in Keratinocyte Migration. Adv. Wound. Care (New Rochelle)., 4(4): 213-224. doi: 10.1089/wound.2014.0540.

Sharma, A., Singh, A.K., Warren, J., Thangapazham, R.L., and Maheshwari, R.K. 2006. Differential regulation of angiogenic genes in diabetic wound healing. J. Invest. Dermatol., 126(10): 2323-2331. doi: 10.1038/sj.jid.5700428.

Shirakata, Y., Kimura, R., Nanba, D., Iwamoto, R., Tokumaru, S., Morimoto, C., Yokota, K., Nakamura, M., Sayama, K., and Mekada, E. 2005. Heparin-binding EGF-like growth factor accelerates keratinocyte migration and skin wound healing. J. Cell. Sci., 118(11): 2363-2370.

Soneja, A., Drews, M., and Malinski, T. 2005. Role of nitric oxide, nitroxidative and oxidative stress in wound healing. Pharmacol. Rep., 57: 108-119.

Spravchikov, N., Sizyakov, G., Gartsbein, M., Accili, D., Tennenbaum, T., and Wertheimer, E. 2001. Glucose effects on skin keratinocytes implications for diabetes skin complications. Diabetes., 50(7): 1627-1635.

Sumi, Y., Muramatsu, H., Hata, K., Ueda, M., and Muramatsu, T. 2000. Midkine enhances early stages of collagen gel contraction. J. Biochem., 127(2): 247-251.

Turner, C.E. 1998. Molecules in focus Paxillin. Int. J. Biochem. Cell. Biol., 30(9): 955-959.

Unoki, K., Okubo, A., Arimura, H., Uehara, F., Muramatsu, H., Kadomatsu, K., and Muramatsu, T. 1995. [Beneficial effect of a retinoic acid responsive gene product, midkine, on constant light-induced retinal damage in albino mice]. Nippon. Ganka. Gakkai. Zasshi., 99(6): 636-641.

Weckbach, L.T., Gola, A., Winkelmann, M., Jakob, S.M., Groesser, L., Borgolte, J., Pogoda, F., Pick, R., Pruenster, M., and Müller-Höcker, J. 2014. The cytokine midkine supports neutrophil trafficking during acute inflammation by promoting adhesion via $\beta 2$ integrins (CD11/CD18). Blood., 123(12): 1887-1896.

Werner, S., and Grose, R. 2003. Regulation of wound healing by growth factors and cytokines. Physiol. Rev., 83(3): 835-870. doi: 10.1152/physrev.00031.2002.

Xing, B., Wu, F., Li, T., Qi, S., Xie, J., and Ye, Z. 2013. Experimental study of comparing rhEGF with $\mathrm{rh} \beta \mathrm{FGF}$ on improving the quality of wound healing. Int. J. Clin. Exp. Med., 6(8): 655.

Xu, C., Zhu, S., Wu, M., Han, W., and Yu, Y. 2014. Functional receptors and intracellular signal pathways of midkine (MK) and pleiotrophin (PTN). Biol. Pharm. Bull., 37(4): 511-520. 
513 Xue, M., Le, N.T., and Jackson, C.J. 2006. Targeting matrix metalloproteases to improve 514 cutaneous wound healing. Expert. Opin. Ther. Targets., 10(1): 143-155. doi: $51510.1517 / 14728222.10 .1 .143$.

516 Yamada, H., Inazumi, T., Tajima, S., Muramatsu, H., and Muramatsu, T. 1997. Stimulation of 517 collagen expression and glycosaminoglycan synthesis by midkine in human skin fibroblasts. 518 Arch. Dermatol. Res., 289(7): 429-433.

519 Zhao, S.L., Zhang, Y.J., Li, M.H., Zhang, X.L., and Chen, S.L. 2014. Mesenchymal stem 520 cells with overexpression of midkine enhance cell survival and attenuate cardiac dysfunction 521 in a rat model of myocardial infarction. Stem. Cell. Res. Ther., 5(2): 37. doi: 10.1186/scrt425. 


\section{Figure Legends}

Table 1. Growth factors and TBARS levels in the wound areas of healthy and diabetic rats on sacrificed times (mean $\pm \mathrm{SE}$ ). 
Table 1. Growth factors and TBARS levels in the wound areas of healthy and diabetic rats on sacrificed times (mean $\pm \mathrm{SE}$ ).

\begin{tabular}{|c|c|c|c|c|c|c|}
\hline Parameters & Groups & Hour 0 & Day 3 & Day 7 & Day 14 & Day 28 \\
\hline \multirow{4}{*}{ (ng/100 mg tissue) } & Healthy (control) (HW) & $1.72 \pm 0.40^{\text {A.a }}$ & $1.63 \pm 0.13^{\mathrm{A} . \mathrm{b}}$ & $1.99 \pm 0.23^{\text {A.a }}$ & $2.48 \pm 0.66^{\text {A.a }}$ & $2.5 \pm 0.22^{\text {A.b }}$ \\
\hline & Healthy + Midkine (HM) & $1.72 \pm 0.40^{\text {C.a }}$ & $2.57 \pm 0.29^{\text {BC.a }}$ & $2.83 \pm 0.31^{\text {BC.a }}$ & $3.67 \pm 0.29^{\mathrm{AB} . \mathrm{a}}$ & $4.19 \pm 0.55^{\text {A.a }}$ \\
\hline & Diabetic (control) (DW) & $1.88 \pm 0.28^{\text {B.a }}$ & $2.60 \pm 0.25^{\mathrm{AB} . \mathrm{a}}$ & $2.79 \pm 0.28^{\text {A.a }}$ & $2.01 \pm 0.29^{\mathrm{AB} . \mathrm{a}}$ & $2.69 \pm 0.22^{\mathrm{AB} . b}$ \\
\hline & Diabetic + Midkine (DM) & $1.88 \pm 0.28^{\text {A.a }}$ & $2.19 \pm 0.43^{\text {A.ab }}$ & $2.54 \pm 0.43^{\text {A.a }}$ & $2.77 \pm 0.98^{\text {A.a }}$ & $2.4 \pm 0.43^{\text {A.b }}$ \\
\hline \multirow{4}{*}{$\begin{array}{c}\text { MMP-8 } \\
\text { (ng/100 mg tissue) }\end{array}$} & Healthy (control) (HW) & $70.20 \pm 53.00^{\mathrm{B} . \mathrm{a}}$ & $314.9 \pm 78.97^{\text {A.a }}$ & $92.23 \pm 43.56^{\mathrm{B} . \mathrm{a}}$ & $59.59 \pm 40.68^{\mathrm{B} . \mathrm{a}}$ & $25.39 \pm 12.35^{\mathrm{B} . \mathrm{a}}$ \\
\hline & Healthy + Midkine (HM) & $70.20 \pm 53.00^{\text {A.a }}$ & $67.72 \pm 26.73^{\text {A.b }}$ & $8.65 \pm 1.33^{\text {A.b }}$ & $59.60 \pm 51.81^{\text {A.a }}$ & $22.89 \pm 14.04^{\text {A.a }}$ \\
\hline & Diabetic (control) (DW) & $29.90 \pm 19.32^{\text {A.a }}$ & $3.67 \pm 1.70^{\text {A.b }}$ & $19.97 \pm 14.44^{\text {A.b }}$ & $3.48 \pm 3.33^{\text {A.a }}$ & $3.17 \pm 1.36^{\text {A.a }}$ \\
\hline & Diabetic + Midkine (DM) & $29.90 \pm 19.32^{\text {A.a }}$ & $6.85 \pm 2.77^{\text {B.b }}$ & $1.22 \pm 0.46^{\mathrm{B} . \mathrm{b}}$ & $0.91 \pm 0.16^{\text {B.a }}$ & $0.66 \pm 0.48^{\text {B.a }}$ \\
\hline \multirow{4}{*}{$\begin{array}{c}\text { PDGF } \\
\text { (ng/100 mg tissue) }\end{array}$} & Healthy (control) (HW) & $1.72 \pm 0.62^{\text {C.a }}$ & $15.82 \pm 2.06^{\mathrm{AB} . \mathrm{b}}$ & $17.98 \pm 3.68^{\text {A.a }}$ & $7.92 \pm 4.27^{\mathrm{BC} . \mathrm{c}}$ & $6.08 \pm 1.13^{\text {C.a }}$ \\
\hline & Healthy + Midkine (HM) & $1.72 \pm 0.62^{\text {C.a }}$ & $15.1 \pm 1.87^{\text {B.b }}$ & $18.74 \pm 2.36^{\text {B.a }}$ & $26.02 \pm 2.73^{\text {A.a }}$ & $14.24 \pm 2.80^{\text {B.a }}$ \\
\hline & Diabetic (control) (DW) & $1.81 \pm 0.93^{\text {C.a }}$ & $25.29 \pm 1.52^{\text {A.a }}$ & $18.07 \pm 2.02^{\text {B.a }}$ & $14.40 \pm 1.98^{\text {B.bc }}$ & $16.12 \pm 3.38^{\text {B.a }}$ \\
\hline & Diabetic + Midkine (DM) & $1.81 \pm 0.93^{\text {C.a }}$ & $16.37 \pm 1.07^{\mathrm{AB} . \mathrm{b}}$ & $17.95 \pm 2.23^{\mathrm{AB} . \mathrm{a}}$ & $24.14 \pm 4.46^{\text {A.ab }}$ & $11.50 \pm 5.65^{\text {BC.a }}$ \\
\hline \multirow{4}{*}{$\begin{array}{c}\text { TGF- } \beta \\
\text { (pg/100 mg tissue) }\end{array}$} & Healthy (control) (HW) & $8.45 \pm 2.85^{\text {A.a }}$ & $5.30 \pm 0.69^{\text {A.b }}$ & $8.45 \pm 0.78^{\mathrm{A} . \mathrm{a}}$ & $6.49 \pm 1.85^{\mathrm{A} . \mathrm{b}}$ & $9.93 \pm 1.61^{\text {A.b }}$ \\
\hline & Healthy + Midkine (HM) & $8.45 \pm 2.85^{\text {B.a }}$ & $6.58 \pm 1.32^{\text {B.b }}$ & $10.24 \pm 2.42^{\mathrm{AB} . \mathrm{a}}$ & $13.00 \pm 2.21^{\mathrm{AB} . \mathrm{a}}$ & $14.24 \pm 2.80^{\text {A.a }}$ \\
\hline & Diabetic (control) (DW) & $7.49 \pm 0.56^{\text {B.a }}$ & $11.73 \pm 1.19^{\mathrm{A} . \mathrm{a}}$ & $7.68 \pm 1.46^{\text {B.a }}$ & $7.55 \pm 1.63^{\text {B.ab }}$ & $8.82 \pm 0.92^{\mathrm{AB} . \mathrm{b}}$ \\
\hline & Diabetic + Midkine (DM) & $7.49 \pm 0.56^{\mathrm{AB} . \mathrm{a}}$ & $6.06 \pm 0.56^{\text {B.b }}$ & $9.28 \pm 1.45^{\mathrm{AB} . \mathrm{a}}$ & $10.29 \pm 1.16^{\text {A.ab }}$ & $8.98 \pm 1.78^{\mathrm{AB} . \mathrm{b}}$ \\
\hline \multirow{4}{*}{$\begin{array}{c}\text { VEGF } \\
\text { (pg/100 mg tissue) }\end{array}$} & Healthy (control) (HW) & $206.63 \pm 56.08^{\text {A.a }}$ & $473.55 \pm 92.31^{\text {A.a }}$ & $225.84 \pm 50.41^{\text {A.b }}$ & $405.45 \pm 244.36^{\text {A.ab }}$ & $185.97 \pm 63.98^{\text {A.a }}$ \\
\hline & Healthy + Midkine (HM) & $206.63 \pm 56.08^{\text {C.a }}$ & $323.13 \pm 154.65^{\text {C.ab }}$ & $793.45 \pm 109.94^{\mathrm{AB} . \mathrm{a}}$ & $922.79 \pm 193.16^{\text {A.a }}$ & $454.83 \pm 123.19^{\text {BC.a }}$ \\
\hline & Diabetic (control) (DW) & $166.82 \pm 65.20^{\text {A.a }}$ & $193.75 \pm 100.73^{\text {A.ab }}$ & $206.79 \pm 84.85^{\text {A.b }}$ & $47.34 \pm 10.04^{\text {A.b }}$ & $310.91 \pm 153.14^{\text {A.a }}$ \\
\hline & Diabetic + Midkine (DM) & $166.82 \pm 65.20^{\text {B.a }}$ & $89.70 \pm 42.11^{\text {B.b }}$ & $83.11 \pm 24.90^{\text {B.b }}$ & $435.26 \pm 141.58^{\text {A.ab }}$ & $130.68 \pm 29.48^{\text {B.a }}$ \\
\hline \multirow{4}{*}{$\begin{array}{c}\text { TBARS } \\
(\mu \mathrm{M} / 25 \mathrm{mg} \text { tissue })\end{array}$} & Healthy (control) (HW) & $1.99 \pm 0.46^{\text {A.b }}$ & $0.88 \pm 0.12^{\mathrm{B} . \mathrm{a}}$ & $0.82 \pm 0.10^{\mathrm{B} . \mathrm{a}}$ & $1.06 \pm 0.36^{\mathrm{B} . \mathrm{a}}$ & $1.04 \pm 0.17^{\mathrm{B} . \mathrm{b}}$ \\
\hline & Healthy + Midkine (HM) & $1.99 \pm 0.46^{\text {A.b }}$ & $2.16 \pm 0.97^{\text {A.a }}$ & $1.79 \pm 0.85^{\text {A.a }}$ & $2.25 \pm 1.10^{\mathrm{A} . \mathrm{a}}$ & $0.73 \pm 0.03^{\text {A.b }}$ \\
\hline & Diabetic (control) (DW) & $25.45 \pm 8.72^{\text {A.a }}$ & $0.97 \pm 0.16^{\text {B.a }}$ & $1.11 \pm 0.16^{\mathrm{B} . \mathrm{a}}$ & $1.40 \pm 0.60^{\mathrm{B} . \mathrm{a}}$ & $1.49 \pm 0.19^{\text {B.a }}$ \\
\hline & Diabetic + Midkine (DM) & $25.45 \pm 8.72^{\text {A.a }}$ & $2.32 \pm 1.45^{\mathrm{B} . \mathrm{a}}$ & $0.91 \pm 0.8^{\text {B.a }}$ & $0.79 \pm 0.05^{\text {B.a }}$ & $0.84 \pm 0.13^{\text {B.b }}$ \\
\hline
\end{tabular}

Different letters in the same column $\left({ }^{\mathrm{a}, \mathrm{b}, \mathrm{c}}\right)$, and line $\left({ }^{\mathrm{A}, \mathrm{B}, \mathrm{C}}\right)$ are statistically significant $(\mathrm{P}<0,05)$. 
